\title{
"We are alive": (Mis)Reading Joy Harjo's Noni Daylight as a Yellow Woman
}

\author{
Chelsea D. Burk
}

Running on the Edge of the Rainbow, a 1978 film produced by the University of Arizona, opens with Leslie Marmon Silko sitting on a porch swing, regaling an audience of three with a version of her poem "Storyteller." The poem features three versions of the Yellow Woman, a figure who originates in the Keres Pueblo oral tradition. Delighted giggles punctuate Silko's words, echoing the story's playfulness. As Silko's voice fades, the camera zooms in, framing the storyteller and her fellow porch-swinger, Joy Harjo, whose laughter trails the tale. The film intimates the strong connection to storytelling that binds Silko and Harjo. Harjo named Silko as a particular influence early in her literary career as she added poetry to her artistic repertoire (Bruchac 228). ${ }^{1}$ Literary criticism that discusses the two artists, however, has surprisingly not followed suit. Beyond comparing Silko and Harjo as women writers of native descent, with some emphasis on thematic overlaps, critics have yet to sustain an exploration into Silko's influence upon Harjo's poetry as contemporary writers interrogating gender norms to which dominant culture and the presiding feminism (also called "sisterhood feminism") adhere in the immediate aftermath of the late twentieth-century's women's liberation movement. ${ }^{2}$

By drawing out Noni Daylight's Yellow Woman characteristics, I hope to illuminate another layer of complexity in Harjo's early poetry, which current scholarship predominately overlooks. I also aim to reify the importance of Yellow Woman and Noni Daylight for feminist literary scholarship and teaching. In the midst of sisterhood feminism's universalizing rhetoric that privileged a white liberal agenda, Silko and Harjo approach womanhood as polyvocal and uniquely situated. Like the Yellow Women in Silko's oeuvre, the Noni Daylights of Harjo's poetry insist that wom- 
en must learn how to tell one's story in order to reject both the normative narratives Anglo-American culture projects that restrict women's sexual expression and the counter-narratives posited by mainstream feminists. ${ }^{3}$ Noni Daylight and Yellow Woman exist between the phenomenology of their lived experiences and the storytelling event. Somewhere among the differences and similarities that attend each story they tell as representations of the culturally-inflected idea of "woman," Noni Daylight and Yellow Woman legitimize women's unsaid and previously unsayable encounters. In so doing, Yellow Woman and Noni Daylight assert that each woman's experiences, as they simultaneously reflect and reject normative gender narratives, deserve listening. They employ a poetics of survivance, a concept with which Gerald Vizenor describes interventions by people of native descent into dominant identity politics and the inextricable lived violences that accompany colonization. Silko and Harjo's figures, like mainstream feminism, reject exceptionalism in favor of community, but do not repeat sisterhood feminist's liberal homogenizing impulse. Each Noni Daylight and Yellow Woman extends, contradicts, and compromises how dominant American culture and liberal feminist counterculture define womanhood. Their voices call out in radical cacophony, expanding the definition of feminist storytelling, of stories worth telling.

\section{Historical Contexts: Who Nightrides with Noni Daylight?}

Critical conversation that engages Silko's work overflows with ruminations on her depiction of Yellow Woman (also called Kochininako), who Silko showcases in her 1981 memoir Storyteller. The name "Yellow Woman" does not only refer to a specific woman, but translates roughly to "Woman-Woman": in the Pueblo tradition the color yellow signifies woman, much in the same way that pink and blue connote gender for Anglo-European Americans (Allen 88). In comparison to scholarly engagements with Noni Daylight, the criticism that accompanies Silko's Yellow Woman on her journeys predominately celebrates her nuances. Elizabeth Hoffman Nelson and Malcolm A. Nelson succinctly describe traditional Yellow Woman stories as, "involv[ing] a young woman who wanders away from the pueblo and either goes with, or is abducted by, a ka'tsina spirit from the mountains” (121). That she somehow leaves the pueblo is the most consistent aspect of Yellow Woman stories. Otherwise, as Nelson and Nelson point out, "Sometimes she is killed by the ka'tsina or her husband; sometimes she returns to the pueblo with a renewed spirit, and the tribe benefits from her encounter" (121). These variations allow Yellow Woman to present women's experiences without the homogenization and privileging that usually accompanies universalizing gestures. While the tales always begin with the Yellow Woman departing, her encounters and decisions remain in question. Will she fall in love with Buffalo Man and die rather than be parted from him, as in Silko's "Cottonwood Part Two: Buffalo Story" (Storyteller)? Or will she return to her husband after a brief rendezvous, as she does in "Yellow Woman" and "Storytelling” (Storyteller)? In the oral tradition and in Silko's stories, Kochininako's decisions are not predetermined. This ambiguity allows her to, in Silko's own words, "represen[t] all women” because "[h]er deeds span the spectrum of human behavior" ("Yellow 
Woman and a Beauty” 70). Her decisions, and therefore her story, cannot be plotted.

Yellow Woman presents both unification and alterity, belonging to the tribe and maintaining separation from her people. She constantly crosses boundaries. In so doing, she destabilizes binaries like the personal and the community, life and death, suffering and joy. With each iteration, she posits different ways of being. Each Yellow Woman explores another facet of relationships and responsibility, not only to others as a mother, daughter, sister, wife, and community member, but to herself. Yellow Woman stories complicate archetypal, universalist representations of "Woman”; as women's needs in the culture change, storytellers adapt Yellow Woman tales to include new situations and iterations of those who identify and are identified as women.

Silko's Yellow Woman stories carry on this tradition. Her Kochininakos respond to women's positions in the immediate aftermath of late twentieth-century women's liberation. Although Silko places her Yellow Women in the mythical past and in her contemporary moment as an author, each Yellow Woman struggles with dominant American culture's gender narrative that positions women in a set trajectory that culminates in the heteronormative nuclear family. Western gender norms do not only impose upon native cultures from the dominant culture. Through the ongoing process of colonization throughout the twentieth century, they already inflect the oral storytelling tradition that inspires Silko. The oral tradition from which Yellow Woman emerges is not untouched by Western patriarchy. Oral traditions exist in the moment, reacting to immediate forces and lived experiences from the present tense (Allen 86). By virtue of their immediacy, oral stories can alter to reflect the dominant culture's values, like misogyny, without the speaker's awareness. Laguna Pueblo scholar and writer Paula Gunn Allen explains:

The oral tradition is a living body. It is in continuous flux, which enables it to accommodate itself to the real circumstances of a people's lives. That is its strength, but it is also its weakness, for when a people find itself living within a racist, classist, and sexist reality, the oral tradition will reflect those values and will thus shape the people's consciousness to include and accept racism, classism and sexism, and they will incorporate that change, hardly noticing the shift. (86)

We cannot read traditional Yellow Woman stories without also taking into consideration how colonization resulted in multiple, converging histories that inflected the presentation of womanhood in the Keres Pueblo oral tradition from which she originates.

In Silko's hands, Yellow Woman takes on a new valence that both honors and complicates the Kochininakos of the oral tradition. Yellow Woman becomes a figure of what Gerald Vizenor terms survivance: "Survivance is an active sense of presence, the continuance of native stories, not a mere reaction, or a survivable name. Native survivance stories are renunciations of dominance, tragedy, and victimry. . . . Postindians are the new stories of conversions and survivance; the tricky observance 
of native stories in the associated context of postmodernity" (vii-viii). Postindian survivance stories may play upon, but also upset, the idea of "the indian" in American culture. As Vizenor asserts, "indian” is a romantic identity that the colonizers projected and continue to project upon people who inhabited the land before and after it became the United States in order to justify colonization and elide native peoples' presence. Yellow Woman unsettles the colonizers' representation of native women as silent objects of a white audience's gaze, like Pocahontas, or as tools for white men's use, like Sacajawea (Harjo "Becoming the Thing Itself” 13). In the face of the representation "indian," Silko's Yellow Women deftly side-step cooptation into an enforced identity of the silent, objectified Indian woman. ${ }^{4}$ Each telling not only upsets the stereotype, but rejects the possibility that a stereotyped identity can encapsulate women of native descent. Yellow Woman is a singular noun that refers to an unassimilable plethora of women's experiences and potentialities. The only thing we know for sure about Yellow Woman is that we will receive her story. We do not know who she is; we do not know what action she will take. In juxtaposition to the silent images of Pocahontas and Sacajawea, with each telling, Yellow Women overflow the totalizing socio-cultural interpellation of "Indian woman.” They break the ringing silence of violent representation, singing their own stories in harmony and in dissonance.

Harjo's early poetry features a similar figure of survivance named Noni Daylight. Various Noni Daylights weave through the two collections that immediately followed Harjo's first book of poetry, The Last Song (1975): What Moon Drove Me To This? (1979) and She Had Some Horses (1983). Whereas Silko's Yellow Women signify on a figure distinctly situated in a specific cultural tradition-that of the Keres Pueblo peoples_-Noni Daylight emerges without definitive ties to a certain tribe or tribes. Harjo identifies as a member of the Mvskoke/Creek nation; however, her autobiographical writings and interviews illustrate an appreciation of the contradictions that inhere in claiming only one genealogy, one inheritance, in contemporary colonial America. ${ }^{5}$ However, like Yellow Woman, Noni Daylight's name positions her as a figure of etymological survivance. Noni plants originate from the Pacific Islands, including Hawai'i, and are used for dye and for medicinal purposes ("noni, n.”). The Oxford English Dictionary's entry on the word indicates that "noni” was a native term with subtle variations ("noni” in Hawaiian; "none” in Maori) that entered the English language during colonizing exploits in the late eighteenth and early nineteenth century. In a twentieth century context, "Noni" carries the trace of precolonial cultures. As an occurrence in English-language poetry, "noni” reflects the surviving presence of natives in modern America. "Noni” juxtaposes "daylight," a portmanteau word with etymological origins in Old English (“daylight, n.”). The combination - Noni Daylight—suggests a figure tied to multiple histories that collide, entwining the histories without resolving them into a flat semblance of unity. Rather than symbolizing womanness in a specific cultural milieu like the name "Yellow Woman,” Noni Daylight represents native women's survivance within converging and conflicting cultures.

Nearly every review and interview that mentions What Moon Drove Me to This? and She Had Some Horses identifies Noni Daylight as an intriguing, unusual wom- 
an. However, rather than exploring Noni Daylight's many iterations and contradictions, since native literatures scholar Andrew Wiget described the figure as Harjo's alter ego a quarter of a century ago, subsequent critics have built their arguments around this foundational assumption. ${ }^{6}$ In 1989, Wiget wrote the first critical work to focus exclusively on Noni Daylight: "Nightriding with Noni Daylight: The Many Horse Songs of Joy Harjo.” In the essay, Wiget asserts that, "What the poet knows, Noni radically lives, and the danger of it frightens even the poet, Noni's 'otherself'..." (188). Wiget founds his argument upon this affiliation, suggesting that Harjo lives her fears through Noni, who serves as an alter ego figure or "otherself." Given the minimal attention native writers received through the mid-1980s, focusing on Noni Daylight was a shrewd move on Wiget's part. In calling attention to this figure rather than limiting his scope to a particular collection, Wiget draws notice to seven poems that span two under-discussed books of Harjo's poetry. ${ }^{7}$ Moreover, Wiget frames Noni Daylight's persistence between texts not just as a character progression, but as exemplifying "the nature, power and direction of growth in Joy Harjo's voice" (186).

In response to Wiget's focus on Noni Daylight, subsequent critics have embraced his reading with few exceptions. ${ }^{8}$ Nancy Lang also reads Noni Daylight as a consistent character. She cites Wiget's article as "help[ing] to give clarity to much of Noni Daylight's seemingly erratic behavior" (43). The "erratic behavior" that frustrates Lang and Wiget's interpretation of Daylight in fact aligns with Harjo's central project in She Had Some Horses. The collection revels in contradiction and discrepancy, as the titular poem's final lines demonstrate: "she had some horses she loved/ she had some horses she hated./ These were the same horses" (63). Wiget's interpretation of Noni Daylight limits her implications insofar as it assumes that Harjo could not adequately express herself in word and in action, so she projected her fantasies onto this figure. Laura Coltelli's entry on Harjo in The Cambridge Companion to Native American Literature solidifies Wiget's interpretation. Coltelli introduces the figure as, "Noni Daylight, Harjo's alter ego," effectively canonizing Noni within the delineations of Wiget's description (286). ${ }^{9}$

While interpreting Noni Daylight as Harjo's alter ego shines light upon an important facet of the figure and Harjo's voice, the critical trajectory implies that this is the primary, perhaps even the only, way in which to approach Noni. ${ }^{10}$ Scholars approach Silko's Yellow Woman with greater flexibility. The two figures receive staggeringly different levels of critical attention for two apparent reasons: 1) As told by Silko, Yellow Woman stories refuse strict delineations into literary categories, spurring ample debate, and 2) Harjo does not overtly align Noni Daylight with the Mvskoke/Creek storytelling tradition in the way that Silko calls attention to Yellow Woman's ties to Laguna Pueblo stories. ${ }^{11}$ I posit another mode of interpretation that reopens the critical conversation surrounding Noni Daylight. By reading Harjo's Noni Daylights as a figure similar in spirit and effect to Silko's Yellow Women, I hope to unsteady the foundation Wiget laid over twenty-five years ago, drawing upon Vizenor's concept of survivance as a tool with which to reframe the figures. 


\section{From Daylight to Daylights: The Implications of Noni's Yellow- Woman Plurality}

As women of native descent growing up in twentieth-century colonized America, both Leslie Silko and Joy Harjo are well acquainted with resistance to their presence. ${ }^{12}$ Silko describes how as a child growing up in the Laguna pueblo, both white tourists and fellow Laguna people rejected her for "look[ing] different, because [she] was part white" ("Yellow Woman" 63). Harjo similarly discusses her experience as a person whose heritage destabilizes strict cultural boundaries ("Exploring the Depths" 35-6). In Harjo's poetry, there is also the concrete imperative to tell stories that express American Indians' experiences and to which they can relate. Speaking about the violence in native communities and high suicide rate amongst teenagers, Harjo says, "The old stories, fairy tales, animal tales and such all include violence-but there are intimate connections between what occurs and meaning in our lives. Then you add being an Indian teenager to the equation and most likely you don't look like these people, you don't belong to the overriding story except as an Indian. And every day you're reminded of this” (25). Through Noni Daylight, Harjo makes room for a plurality of women's experiences that dominant culture's racist hegemony attempts to elide. She counters the violence of omission, positing alternate ways of being that actively undermine the idea that native peoples do not exist except in the imposed identity of "Indian." ${ }^{13}$ Her work speaks to whoever will sit and listen to stories that trouble dominant discourse. In Harjo's words, "There is always resistance to anyone who is out there doing anything that crosses boundaries: of genre, culture, country, language, etc. ... I trust the work will find its way ...” (35).

Alongside Anglo-American racism, as women of native descent writing literature that hovers at the edge of the women's movement, Silko and Harjo's feminist figures also collide with the predominately white, liberal mainstream cohort's separatist ethos that at times echoed the rhetoric of binaries they aimed to upset. ${ }^{14}$ Audre Lorde commented on the binaries, arguing, "By and large within the women's movement today [1980], white women focus upon their oppression as women and ignore differences of race, sexual preference, class, and age. There is a pretense to a homogeneity of experience covered by the word sisterhood that does not in fact exist" (116). ${ }^{15}$ A 2009 anthology edited by white poet Honor Moore epitomizes the continued absence of writings by women of native descent in the canonized construction of the women's movement. Although Moore aims to provide "a portrait of how the inner lives of women came into language during that crucial decade and a half [1966-1982]," the collection neglects to include any writings by women of native descent (xxix). The anthology underscores how mainstream feminism continues to alienate women of native descent's feminist offerings.

The selections that Moore chose to include in the anthology illustrate how exceptional Harjo's Noni Daylight and Silko's Yellow Woman are as feminist figures. Silko and Harjo mobilize poetry to explore women's subjectivities through multiple encounters with Yellow Woman and Noni Daylight. However, they resist repeating the existing ideology and counter-ideology that pit men and women, heterosexuality and homosexuality, and masculinity and femininity, in a reductive positive/negative binaric formulation. This does not delegitimize the troubling encounters with men of 
which contemporaneous women speak, like those Marge Piercy gestures towards in "Rape Poem” and Sonia Sanchez speaks of in "a poem for my father," but expands women's options for how they consider themselves in relation to men. During an interview immediately preceding the publication of She Had Some Horses, Harjo reflects that women in her poems differ from women in poetry by Anglo-American writers. Her women, she asserts, "reach an androgynous kind of spirit where they are a very strong people. They're very strong people, and yet to be strong does not mean to be male, to be strong does not mean to lose femininity, which is what the dominant culture has taught” (Bruchac 227). Noni Daylight and Yellow Woman present a variety of strengths without limiting themselves to either normative or iconoclastic gender norms. As women of native descent writing on the outskirts of dominant patriarchal culture and dominant feminist counter-culture as the 1980s began, Silko and Harjo offer examples of unsettled, contradictory, and indeterminate femininity.

Although Silko presents various Yellow Women throughout Storyteller, the women that punctuate the poem "Storytelling" most overtly demonstrate the kind of narrative ambiguity and emphasis on storytelling that connects them to Noni Daylight as figures of survivance. The poem begins with an address to readers that urges them to "understand/ the way it was/ back then,/ because it is the same/ even now" (90). This explicit connection between now and then epitomizes the urgency behind telling Yellow Woman stories that map multiple ways to be a woman. The poem flows into three sections. The first section, told in the third person, presents a traditional Yellow Woman and Buffalo Man tale in which they meet near a river. She returns ten months later with twins to her husband's voice, demanding: "You better have a damn good story” (91). Then, we receive a date: 1967. A TV news report describes police chasing after "four Laguna women/ and three Navajo men" leaving a "trail/ of wine bottles and/ size 42 panties" in their wake (92-3). From the wine bottles to the size 42 panties, this story adapts the traditional seduction story to a twentieth century setting. ${ }^{16}$ The final speaker in the poem also frames her story in the contemporary moment. She describes her Buffalo Man as if the reader is familiar with him: "It was/ that Navajo/ from Alamo,/ you know,/ the tall/ good-looking/ one” (92). The story that follows details a violent abduction; and yet, final stanza clues the reader into its falseness: "My husband/ left/ after he heard the story/ and moved back in with his mother./ It was my fault and/ I don't blame him either./ I could have told/ the story/ better than I did” (93). At first it may seem like this Yellow Woman relates the events to her husband in order to expiate herself. However, her awareness that she "could have told/ the story/ better" suggests otherwise. This Yellow Woman capitalizes off the formula of Yellow Woman stories in which a man carries a woman away. In a twist of irony, this speaker molds her story to fit the tradition in order to escape her husband. Here, invoking a traditional story enables Yellow Woman to pursue her own desire. Storytelling invites and incites change, even as it reflects cultural norms. The three Yellow Women whose stories converge in "Storytelling" saturate the canvas of possibility with vivid colors that by turns clash and compliment, creating an anti-map overflowing with the same indeterminacy and potential that infuses Noni Daylight. The temporal dissonance between these women united under the action “storytelling” reiterates Yellow Woman's continued presence as a 
figure of survivance.

Harjo articulates various modes of women's survivance through the Noni Daylights that span seven poems. Four poems mention Noni Daylight in What Moon Drove Me to This? while three can be found in She Had Some Horses: "The First Noni Daylight," "Origin," "Someone Talking," and "Evidence” in the former, "Kansas City," "Heartbeat," and "She Remembers the Future” in the latter. ${ }^{17}$ One way of demonstrating how diverse these Noni Daylights are is to attend to how the speaker frames each iteration. "Kansas City” begins by placing Noni Daylight as a metaphor, saying, "Early morning over silver tracks/a cool light, Noni Daylight's/ a dishrag wrung out over bones/watching trains come and go" (26). The enjambment renders the apostrophe attached to "Daylight" uncertain, so that Noni Daylight immediately straddles being ("Noni Daylight [is]") and possessing ("Noni Daylight's"). When the next line begins, the article "a” displaces both preceding interpretations. In the presence of "a," Noni Daylight registers as a part of what Harjo terms “American capitalist overculture"-a person whose existence revolves around consumption, which the possessive apostrophe denotes - while she also exists beyond the concrete as a metaphor (Soul Talk 52-3). The apostrophe's ambiguity extends interpretive space to comment on women's position within American capitalism as Irigaraian commodities, as well as consumers. The punctuational epiphany emphasizes Noni's existence as a subject affected and inflicted by language, gesturing towards the kind of figuration that also partially attends Yellow Woman. One is not, nor cannot be, the one and only Yellow Woman, but $a$ Yellow Woman, one of many who share unique experiences of womanhood through the medium of language. In "Yellow Woman," the speaker wavers between accepting herself as a Yellow Woman and questioning her relation to the figure, "because," as she says, "[Yellow Woman] is from out of time past and I live now” (54). Just as this Yellow Woman recognizes Yellow Woman's simultaneous universal and particular phenomenology as they intersect in the storytelling act, Noni Daylight exists in conjunction as both a woman watching trains and a connective skein that entwines disparate iterations of being, providing further valences of what it means to be a woman of native descent in late twentieth-century America.

The title of "The First Noni Daylight" extends this connection. Of course, the title most obviously denotes that this is the first poem in which Noni Daylight appears. While the phrase "the first" may seem to support an interpretation like Wiget's insofar as it could mark the beginning of a linear progression that follows a single Noni Daylight's life, it also subtly draws the reader's attention to the two variations of Noni Daylights the poem offers. Like the apostrophe attaching the "s" to Noni Daylight in "Kansas City," "the first” in this poem's title maneuvers the interpretive focus in multidimensional directions that alternately blur and clarify Noni's position. "[T]he first" refers to the first Noni Daylight in the poem, the woman in the first stanza who tries to commit suicide: "noni daylight tried it/ saturday night special, the little white pills/ whiskey and a note [sic]" (27). The second and final stanza names "noni daylight” again, but with a variation: "daylight survived and her lover/ was oh so guilty and promised never/ to love anyone else again/ and couldn't,/ tied to noni daylight's/ recovery bed” (27). Here, the speaker emphasizes “daylight” as an am- 
biguous word. Formally, the poem resists the hierarchy capitalizing proper nouns imposes (reminiscent of bell hooks and her notorious lowercase nom de plume) and creates a moment of indeterminacy in the poem. Did Noni Daylight, the first Noni Daylight we witness in the poem, survive? Or, did daylight, the sun rising and shining, persist without Noni? Even the pronoun "her" participates in this ambiguity; poetry is no stranger to personification or the pathetic fallacy. The speaker relies upon the first name's presence and absence to emphasize the possibilities "daylight" holds.

Harjo casts the other Noni Daylights in syntax that extends their various functions and experiences. "Origin” begins with the name Noni Daylight, immediately positioning her in a past moment of action that juxtaposes her present tense existence in "Kansas City": "Noni Daylight left the morning/ at Bluewater Lake” (33). "Heartbeat" and "She Remembers the Future" reframe Noni Daylight even further. "Heartbeat” begins, "Noni Daylight is afraid," privileging her existence in the present with simple but urgent syntax (31). "She Remembers the Future” opens with a sequence that makes Noni Daylight's position as a figure in a narrative obvious by denoting her voice in the third person: “'We are closer than/ blood,' Noni Daylight/ tells her” (41). The poem "Evidence” similarly distances the poetic voice from Noni Daylight, but through a first person speaker: "Lights were caught in my apartment./ What could we do, everyone gone,/ Except for Noni Daylight” (55). The differences between each Noni Daylight do not preclude the figures' connections, but equally do not exclude them. The bonds that link the Noni Daylights to one another do not align through a single narrative that correlates with Harjo's biography, as Wiget and his followers assert. Each poem reveals its own Noni Daylight situated in her own temporal moment just as much as it invokes the other Noni Daylights as they struggle to articulate themselves in spite of their erasure by dominant American culture.

Storytelling in the Yellow Woman tradition acknowledges, and indeed establishes the urgency of survivance behind disclosing various experiences of womanhood. In an introduction Silko added to the 2012 edition of Storyteller, the writer "imagine[s] that at first humans exchanged stories to acquire knowledge as a survival strategy, to learn to anticipate the many threats and dangers in their world" (xviii). She advocates for telling many versions of stories, saying, "For the Pueblo people, a collective truth resides somewhere within the web of differing versions, disputes over minor points, outright contradictions tangled with old feuds, and village rivalries; thus the ongoing story or history of the Pueblo people continues endlessly” (xx). Stories propose strategies for survival, implicitly including survival through the continuance of colonization. The varying perspectives that contribute to a multiplicity of stories in turn create an "ongoing story" that is constantly in fruitful friction. This celebration of contradictory multiplicities complicates the exclusionary politics of white, Western feminism that prioritize certain understandings of womanhood over others, as well as the dominant white myth of the absent Indian. Silko rejects '70s mainstream feminism's suggestion that some women's stories are irrelevant. Her Yellow Women expand the canon to include alternative examples of female agency and subversion.

Harjo imbues her conception of storytelling with a similar emphasis on survivance. She states in her memoir Crazy Brave: "A story matrix connects all of us . . 
And the story begins exactly where it is supposed to begin. We cannot skip any part” (28). Harjo's emphasis on where a story "begins” echoes the beginning of each Yellow Woman story, which all stem from a woman leaving her home but end quite differently in each telling. The variety of plots Kochininako traverses allows the audience and Yellow Woman to experience diverse iterations of womanhood that extend into the contemporary moment. For Harjo and Silko, storytelling carries the responsibility of others' survival insofar as each story's unicity complicates our collective understanding of what it means to be a woman. These writers revise dominant patriarchal and feminist narratives that undermine women's pleasure and agency in heterosexual relationships, expanding narrative space by insisting that every variation and expression of womanhood maintains validity. Yellow Woman and Noni Daylight do not "skip any part” of the spectrum of women's experiences, including sexual exploration and encounters, acknowledging that each woman's life inflects broader narratives of womanhood and identity in American culture. Each carries with them potential for the next telling, another story that carves further nuance into to "the collective truth" in the "story matrix [that] connects all of us."

While the urgency behind storytelling in Silko's work has been widely discussed since she released Storyteller, critical focus surrounding Noni Daylight attends less diligently to how each version of Noni Daylight, in its singularity, suggests a deep attention to how women craft their own stories. "Someone Talking" features Noni Daylight finally speaking to "the man of words," whose name and, as previously mentioned, syntactic position suggest how overwhelming his presence can be. ${ }^{18}$ Throughout the poem, Noni considers how to communicate with men, or the same man-the pronoun "he" follows Noni through memories and into the present moment, so that its referent becomes impossible to definitively trace. In each situation, however, Noni wonders how to interpret men's voices as they tell their stories: "Maybe the man of words speaks/ like the cricket./ Noni Daylight/ hears him that way" (46). This Noni exists in a state of perpetual misunderstanding, one heightened by the man's dominant position over her.

Where "Someone Talking" echoes the gender dynamics many women writers of that moment expressed, "Kansas City" offers an alternate version of heterosexual relationships. In "Kansas City,” Noni Daylight considers all of the children she has birthed by men of varied racial descents. She reflects on her life and these men, thinking, "Early morning,/ if she had it to do over/ she would still choose:/ . . . all of them,/ their stories in the flatland belly/ giving birth to children/ and to other stories/ and to Noni Daylight" (27). In the last lines, the men become "their stories." The stories, not the men, syntactically generate "children," "other stories," and "Noni Daylight.” This progression suggests that the men's individual and collective pasts, presents, and futures combine within and beyond the children they participate in creating, altering Noni Daylight insofar as they contribute to her story. While the men's influence on Noni could destabilize her agency, the sequence's beginning affirms that Noni "would still choose" to incorporate and be incorporated into these stories. That Noni affirms, even celebrates, her relationships with men positions Harjo as an anomaly among women writers in the late 1970s and early 1980s, when mainstream women's poetry focused on their existence and prerogatives apart from 
men or without men as their focus. In a gesture of survivance, Noni Daylight revises such an approach to heterosexual relationships in order to emphasize the past's imprint on the present.

In the Noni Daylight poems, Harjo meditates on how living outside dominant narratives can cause fear to overtake one's life. Harjo concludes She Had Some Horses with "I Give You Back," an incantation that confronts fear as it reflects what it means to live as a woman of native descent in the United States. Throughout the poem, the speaker "give[s] back" fear to itself: "I give you back to the soldiers/ who burned down my house, beheaded my children,/ raped and sodomized my brothers and sisters./ I give you back to those who stole the/ food from our plates when we were starving” (71). The poem almost reads as an exorcism, yet the concluding lines intimate a more complex and contradictory relationship to fear than one of binaric good/evil. The speaker embraces fear: "But come here, fear/ I am alive and you are so afraid/ of dying” (72). In an interview with Angels Carabi, Harjo describes where she believes fear originates—-here in particular relation to racism—saying, “ . . . fear is the cause of racism. Fear of oneself. You don't try to control another group by any deviant means - and racism is a deviant means - unless you are afraid of yourself, unless you feel insecure about your own power" (4). By celebrating narrative indeterminacy, Harjo works towards destigmatizing not knowing, washing away the insecurity that attends Western normativities in their various forms. Through showing an array of Noni Daylights whose comfort with themselves and others vary, Harjo confronts the same heterosexual, patriarchal normativities that were the vanguard for second wave feminists, but with careful attention to the complexities that arise when shifting cultural norms on individual, community, and national levels. Her celebration of indeterminacy recalls the Yellow Woman, who maintains strong connections to her past while simultaneously unfolding new possibilities for women's futures.

Like Yellow Woman, the Noni Daylights of "Heartbeat" and "Evidence" multiply the voices within the story matrix, opening a space that validates the experience of indeterminacy that native women may face in a culture that attempts to erase their presence. In "Heartbeat," Noni Daylight is a mother. Her own mother's absence haunts her to the point where the past appears predatory: "She was curled inside her mother's belly/ for too long. The pervasive rhythm/ of her mother's heartbeat is a ghostly track/ that follows her" (31). The pulses of her mother's heartbeat connect Noni to the point of origin in the story of her life and beyond, to her mother's past and presence in the world, extending ever further back in time. The sound and energy of Noni's mother's heart call out to her mother's own story, her father's story, their communities' stories, and so on, as the Noni Daylight in "Kansas City” recognizes. The speaker in "Heartbeat" repeats the phrase "a way": "She wanted a way to see the stars/ complete patterns in her hands, a way to hear/ her heart, her own heart" (31). The repetition of "a way" suggests that Noni Daylight struggles to find a medium through which she can understand her existential position as a person living in a culture bent on her erasure. However, in seeking “a way," Noni stands on the brink of discovery, drawn to the edge by the ache for connection, "to see the stars/ complete patterns in her hands.” Compared to the other Noni Daylights in She Had Some 
Horses, the Noni Daylight of “Heartbeat” struggles to accept her position within a broader narrative. She does not realize that indeterminacy does not preclude agency or authenticity. Survivance persists through moments when one's life story does not fit into dominant narratives. Indeed, survivance presupposes a disconnect between the presiding story of the vanished Indian and native peoples' continued, insistent presence.

Harjo and Silko's stories of survivance also question the presumed goal of poetry the mainstream women's movement celebrated: "realiz[ing]" one's "inner sel[f]" (Vickery 37). While some Yellow Women and Noni Daylights find comfort in a sense of inherent identity, Silko and Harjo also present women who struggle to articulate themselves. In "Evidence," the speaker who sees herself as separate from Noni Daylight echoes the protagonist in "Yellow Woman." Both iterations voice fear because they do not have the words for who they are and what they want. This Yellow Woman cannot name her emotions. Throughout the short story, she repeats that she has “a feeling” or, in slight variation, “a strange feeling” (55-56). Similarly, the speaker in "Evidence” confides: "It's what I don't remember/ that terrifies./ Something about wanting out" (55). What "terrifies” the speaker remains ambiguous. Does she fear not knowing, or does she fear leaving? The speaker struggles to find concrete words to express herself, only recalling "something about wanting out" (emphasis mine). As figures that acknowledge all dimensions of women's experiences, this Noni Daylight and Yellow Woman counter mainstream feminism's insistence that liberation relies on women articulating who they are and what they want. Harjo and Silko normalize the inability to articulate one's self just as they acknowledge the fear that attends living on the outskirts of non-normative narratives. From at times hesitant, irresolute positions, Silko's Yellow Women and Harjo's Noni Daylights each ruminate on their agential potency and the responsibility they hold over their own story. Within each uncertainty lies one surety: that these stories bear telling.

The examples I provide from Harjo's and Silko's works far from exhaust the potential correlations between Noni Daylight and Yellow Woman. They do, I hope, begin to augment the critical hush that surrounds Noni Daylight, leaving her stagnant in an interpretation that has defined her for over a quarter of a century. Reading Noni Daylight through the Yellow Woman in turn rejuvenates the Yellow Woman as her tale steps beyond her name and into a constellation of other stories exploring sites of native women's survivance in the face of the twentieth century's dominant narratives and narratives of domination. Scholars would do well to revisit women that Harjo introduces in her earlier poems in order to reassess our own expectations for and preconceived notions of what kinds of women's stories belong to the "women's movement," a misleadingly simple label for what decades of scholarship acknowledges was a series of pluralistic, polyvocal events. Noni Daylight and Yellow Woman legitimize spaces of contradiction, uncertainty, and inconsistency that inflect women's lives as they attempt to speak with authenticity from within a cavalcade of projected expectations and imperatives. In spirit and in form, Joy Harjo and Leslie Silko voice other ways of being, other stories of and between solidified notions of self, echoing with the insistent refrain, "we're alive/ we are alive." 


\section{Notes}

1 Harjo describes how her relationship to poetry began in adulthood in a number of texts. For most of her early years, she considered herself a visual artist and a musician. Some of Harjo's most notable descriptions can be found in her memoir Crazy Brave (2012), in a 1985 interview with Joseph Bruchac, and in a compilation of the artist's interviews, essays, and photographs, Soul Talk, Song Language: Conversations with Joy Harjo (2011).

2 For example, Jeanne Perreault connects the recurring themes of dreams and memory in "New Dreaming: Joy Harjo, Wendy Rose, Leslie Marmon Silko" (1994).

3 Harjo adamantly and repeatedly rejects American culture, describing it as an "overculture," or an ideological system based on capitalistic exchange rather than ties to other beings (Soul Talk 52-3 and "Classroom"). Throughout this essay, I refer to "American culture" with her insightful definition in mind.

4 Clarity and consistency compel me to note that from here on, I do not place "indian" in quotes, instead capitalizing the word in order to denote its status as an identity marker. I switch between American Indian, women of native descent, and native-each with their own sociohistorical baggage and each existing in spite of levied criticism-depending on the context in which it falls. This is not to confuse readers, but to emphasize how the issue of identity formation and power alters with specific contexts, particularly who speaks and of whom is spoken. As a writer who does not identify as American Indian, native, or a woman of native descent, and who has not been interpellated by others as such, it is important to note the position of privilege from which I write. I welcome any and all corrections, concerns, and responses to my use of identity language.

5 Harjo notes her complex lineage in her autobiography Crazy Brave, pages 19-22.

6 For examples of the attention reviewers, interviewers, and scholars paid to Noni Daylight before Wiget's 1989 article, see the following: Joseph Bruchac's “Interview with Joy Harjo" (1985), Jan Clausen's “American in the Singular" (1984), Carla Kaplan’s "What Moon Drove Me to This? by Joy Harjo; She Had Some Horses by Joy Harjo" (1985) and Jim Ruppert's "Paula Allen Gunn and Joy Harjo: Closing the Distance between Personal and Mythic Space” (1983).

7 The reviews that discuss Harjo's early collections insinuate that despite praise from the likes of Wiget and Zorn, critics who were familiar with Harjo's poetry did not wholly embrace her work. In a dual review of What Moon Drove Me to This? and She Had Some Horses from 1985, Carla Kaplan gives the earlier text muted praise, calling the poems "predictable" (175) and "uncompleted because of the presence of numerous different voices representing the disparate elements of the self" (176). Kaplan's comments become less tentative as she moves to the later poems, calling the voice in She Had Some Horses "stronger, more assured, consistent" (177). The review 
implies that readers should revisit Harjo's previously published works, as if they build upon one another in a continuous story. In a review by Jan Clausen for the Women's Review of Books in 1984 that focuses on She Had Some Horses alone, Clausen emphasizes that although many of the poems that appear in the collection first attained visibility through small press magazines and anthologies, Harjo still receives relatively little mainstream critical consideration. However, Clausen tempers her praise with some criticism of the collection, bemoaning that "some [poems] fall considerably short of the emotional precision and fine-honed language Harjo usually achieves,” and asserting that the organization "puzzle[s]" her (7). In addition to the scholarly interjections by Zong and Wiget that outline native women poets' relationship to the American literary canon in the 1980s, Kaplan and Clausen's reviews demonstrate the fraught position Harjo held amongst those who already devoted time and ink to her work. Over two decades after Wiget attempted to solidify Harjo's literary standing, her poetic validity is not in question as it once was. By the 1990s, Harjo's work received considerable accolades when her book of poems, Secrets from the Center of the World (1989) and a collection of her work, In Mad Love and War (1990), won the prestigious Delmore Schwartz Memorial Poetry Prize and the William Carlos Williams Award (Scarry 286). Now that Harjo stands as a respected poet to whom scholars give notice, revisiting and revising critical interpretations of her earlier work pose less danger.

8 Notably, one early critical essay stands apart from the reception I trace in this essay. Jim Ruppert wrote an article for American Indian Quarterly, a journal focusing on interdisciplinary studies regarding native peoples, in 1983 that places the Noni Daylight poems from What Moon Drove Me to This? in conversation with Paula Allen Gunn's works. Unlike Wiget and the scholars his interpretation inspired, Ruppert argues that Harjo created Noni Daylight to "live in that distance between the two worlds [of personal and mythic space] or perceptions," separating Noni from Harjo and/or the narrative voice in his readings (31). While Ruppert's interpretation seems to counter what Wiget would argue six years later, his language also implicitly supports conflating Harjo with Noni Daylight. As he introduces Noni, Ruppert calls her "a character of a persona" (31). The word "character" implies fictionality, and therefore presumably distance from Harjo. However, the label "persona,” which the Oxford English Dictionary defines as "An assumed character or role, esp. one adopted by an author in his or her writing," connotes that Noni actually functions as another version of Harjo (“persona, n.”). Although Ruppert's essay is one of the earliest critical publications that explicitly engages Noni Daylight, it is Wiget's interpretation that takes hold in the scholarly community. We can read Ruppert's literary analysis as an indication of ambiguities with which subsequent critics like Wiget will struggle.

9 Wiget's literary-historical milieu helps contextualize his insistence that Noni Daylight reflects Harjo's growth as a poet. His article counters the scholarly trend through the mid-1980s that ignored poetry by people of native descent as worthy of critical attention-a trend that Honor Moore's editorial deci- 
sions in her anthology of poetry from the women's movement emphasize. In an essay that precedes his defense of Noni Daylight, Wiget attempts to garner support for contemporary writers of native descent. Featured in the renowned journal College English, his article brings to light "the previously unremarked absence of attention given to this poetry" (600). Wiget suggests that native poets remain absent from contemporary literary canons because they publish through small presses, which in turn have "very limited access to major markets," and, presumably, also have limited access to scholarly institutions nationally (600). Harjo's early publication history supports Wiget's claim: the small press outlet Reed and Cannon published Harjo's What Moon Drove Me to This?, while another small publisher, Thunder's Mouth Press, oversaw the publication of She Had Some Horses. Wiget's essay contextualizes the plight of institutional recognition native poets like Harjo had to navigate in the ' $80 \mathrm{~s}$.

10 A recent essay by Craig Womack from 2010 suggests that other literary scholars are reconsidering Noni Daylight. Womack only mentions her briefly, but provocatively "suspicion[s]" Noni's presumed heterosexuality in the criticism, opening the field of engagement with Noni to include non-normative sexuality in a way that echoes my insights regarding the figure. Kristine Holmes also contributes to recent ruminations over Noni Daylight. She cites an interview between Laura Coltelli and Harjo that complicates Coltelli's Cambridge Companion entry. Harjo says to Coltelli: “'[Noni Daylight] began quite some time ago, as a name I gave a real-life woman I couldn't name in a poem. Then she evolved into her own person, took on her own life'" (53). In no place does Harjo insinuate that Noni Daylight represents another part of herself. During another interview with Joseph Bruchac, Harjo describes Noni Daylight's origins as "another way for [her] to speak," quipping, "It's like she was a good friend who was there at a time in my life and she's gone on" (227). In both scenarios, Harjo sets a distinct boundary between herself and Noni Daylight: she describes Daylight as "her own person" and "another way for [her] to speak," rather than a part of her psyche or a literary analogue (emphasis mine). Responding to the Coltelli/Harjo interview, Holmes expands the critical conversation to include other ways of glimpsing Noni Daylight. She argues that, "While we can view Noni ... a as [a] 'hellraising' alter eg[o] who symbolize[s], like Coyote, survival and continuance, the poe[t] portray[s] [Noni] in a female-inflected way, setting forth a feminist revision of tricksterism" (46). Holmes does not refute Wiget's interpretation, but nor does she wholly accept it. She implicitly critiques Wiget's one-to-one assertion by aligning Noni Daylight with Coyote, insinuating that the figure resonates on the level of myth as much as she does as a contemporary woman, a valence of Noni that Wiget and his successors do not entertain. Holmes's reading and Womack's suggestion begin the challenging work of throwing doubt upon a canonized interpretation, inviting us to a space in which we might consider Noni Daylight with more nuance.

11 In "Desire's Revision: Feminist Appropriation of Native American Traditional Stories," Victoria Boynton demonstrates how slippery categories become 
when discussing works influenced by oral storytelling and indigenous culture, as well as what she calls "Euroamerican" literature and American culture.

12 Harjo addresses the ghettoization of many writers of difference-primarily those who are not white, male heterosexuals - in an interview with Joseph Bruchac. She mentions discussing "being categorized as Indian writers" with novelist and poet James Welch, along with others.

13 In "Becoming the Thing Itself," Harjo discusses growing up in an American school where "there were no females, there were no Indians, and even though half the class was Indian we read that there were no more Indians" (17).

14 Many contemporaneous feminists and subsequent critics of second wave feminism like Kimberlé Crenshaw have problematized the dominant speakers in the movement's binaric thinking as a means of addressing subjectivity - particularly gender and race. Crenshaw particularly argued that scholars should approach identity through what she terms intersectionality, or recognizing how gender and race compound and overlap in specific situations (1244). See Jennifer C. Nash's "Re-thinking Intersectionality” for a detailed review of the term's origin and subsequent uses that contribute to what Nash describes as the term's twenty-first century situation as a potentially problematic catchall theory.

15 See Thompson's essay, "Multiracial Feminism: Recasting the Chronology of Second Wave Feminism" for an excellent overview of the specific events that demarcate second wave feminist history, as well as for a number of lists that recognize how expansive and inclusive feminist groups were outside of the most visible feminist groups like NOW (the National Organization for Women), which favored white, middle-class, heteronormative women's experiences.

16 See Jacqueline Urla and Alan C. Swedlund's “The Anthropometry of Barbie: Unsettling Ideals of the Feminine Body in Popular Culture” for a thorough overview of gendered body norms in twentieth-century America. Particularly, they overview how the prevailing norms for the "ideal" female body became much more "slim-hipped" between the 1940s and the 1960s; by the seventies, "slenderness and sex appeal ... became the premier concern of postwar femininity" (293).

17 While I at times refer to the poems as they appear chronologically within the collection, I do not do so to impose a linear teleology upon them or to suggest that the Noni Daylights narratively cohere-quite the opposite. Unlike Wiget, Lang, and, to an extent, Holmes, who insist that each poem featuring Noni contributes to an overarching narrative that does cohere even though her age and the space she occupies do not temporally align in a linear fashion, I mention them in this order simply because this is the way Harjo presents the poems.

18 For those familiar with literature by writers of native descent, the phrase "the man of words" echoes one of Kiowa writer N. Scott Momaday's most fascinating stories, entitled "The Arrowmaker," featured in The Man Made of 
Words. As Momaday tells it, the story emphasizes the importance language holds over not only communication, but also our identities-he calls the story's protagonist "the man made of words" (9). While the book was published in 1997, Momaday also mentions the story in his memoir The Names, published in 1976. Harjo notes Momaday's influence on her work in the acknowledgments for Crazy Brave; although we cannot assert for certain that "the man of words" in "Someone Talking” connects to “The Man Made of Words," the thematic similarities bear notice.

\section{Works Cited}

Allen, Paula Gunn. "Kochinnenako In Academe: Three Approaches to Interpreting a Keres Indian Tale.” "Yellow Woman”: Leslie Marmon Silko. New Brunswick: Rutgers University Press, 1993. Print.

Anderson, Byron. Alternative Publishers of Books in North America. $4^{\text {th }}$ ed. Gainesville, FL: CRISES Press, 1999. Print.

Barnett, Louise. "Yellow Women and Leslie Marmon Silko's Feminism." Studies in American Indian Literature 17.2 (Summer 2005): 18-31. Web.

Bowker's Publishers, Distributors \& Wholesalers of the United States, 2001-2002. v. 1. New Providence, NJ: R. R. Bowker LLC, 2001. Print.

Boynton, Victoria. "Desire’s Revision: Feminist Appropriation of Native American Traditional Stories.” Modern Language Studies 26.2/3 (1996): 53-71. Web.

Bruchac, Joseph. "Interview with Joy Harjo." The North Dakota Quarterly 53.2 (1985): 220-234. Print.

Carabi, Angels. “Joy Harjo.” Belles Lettres 9.4 (Summer 1994): 1-5. Web.

Clausen, Jan. “American in the Singular.” The Women's Review of Books 2.1 (1984): 7-8. Print.

Coltelli, Laura. “Joy Harjo’s Poetry.” The Cambridge Companion to Native American Literature. Eds. Joy Porter and Kenneth M. Roemer. 1st ed. Cambridge: 2005. Cambridge Companions Online. Web.

Crenshaw, Kimberlé. "Mapping the Margins: Intersectionality, Identity Politics, and Violence Against Women of Color.” Stanford Law Review 43.6 (1991): 12411299. Print.

“daylight, n.” OED Online. Oxford University Press, September 2014. Web. 15 September 2014.

Gibson, Mary E., Antonia Quintana Pigno and Joy Harjo. "Poetry Reading: Third World Women Poets.” Women's Studies Newsletter 8.3 (1980): 14. Web.

Harjo, Joy. Class Visit to 8:238 "Readings in American Indian Literature.” University of Iowa. English-Philosophy Building, Iowa City, IA. 24 Oct. 2013. Guest Lecture.

---. Crazy Brave: A Memoir. New York: W. W. Norton \& Company, Inc, 2012. Print.

---. She Had Some Horses. New York: W. W. Norton \& Company, Inc. 2008. Print.

---. “What Moon Drove Me to This?” New York: Reed Books, 1979. Print.

Harjo, Joy and Tanaya Winder. "Becoming the Thing Itself.” Soul Talk, Song Language: Conversations with Joy Harjo. Middletown, CT: Wesleyan University 
Press, 2011. 3-26. Print.

---. "Exploring the Depths of Creation and Meaning." Soul Talk, Song Language: Conversations with Joy Harjo. Middletown, CT: Wesleyan University Press, 2011. 31-37. Print.

Holmes, Kristine. “'This Woman Can Cross Any Line': Feminist Tricksters in the Works of Nora Naranjo-Morse and Joy Harjo.” Studies in American Indian Literatures 2.7 (1995): 45-63. Web.

Kaplan, Carla. "What Moon Drove to This? by Joy Harjo; She Had Some Horses by Joy Harjo.” Studies in American Indian Literatures 9.4 (1985): 175-177. Web.

Lang, Nancy. “'Twin Gods Bending over': Joy Harjo and Poetic Memory.” MELUS 18.3 (1993): 41-49. Web.

Lorde, Audre. “Age, Race, Class, and Sex: Women Redefining Difference.” 1980. Sister Outsider: Essays and Speeches by Audre Lorde. Berkeley, CA: Crossings Press, 2007. Print.

Moore, Honor, ed. Poems from the Women's Movement. New York: The Library of America, 2009. Print.

Nash, Jennifer C. “Re-thinking Intersectionality.” Feminist Review 89 (2008): 1-15. Web.

Nelson, Elizabeth Hoffman and Malcolm A. Nelson. “ Shifting Patterns, Changing Stories: Leslie Marmon Silko’s Yellow Women.” Leslie Marmon Silko: A Collection of Critical Essays. Ed. Louise K. Barnett and James L. Thorson. Albuquerque: University of New Mexico Press, 1999. 121-134. Print.

“noni, n.” OED Online. Oxford University Press, September 2014. Web. 15 September 2014.

Perreault, Jeanne. “New Dreaming: Joy Harjo, Wendy Rose, Leslie Marmon Silko.” Deferring a Dream: Literary Subversions of the American Columbiad. Eds. Gert Buelens and Ernst Rudin. Basel, Switzerland: Birkhäuser Verlag, 1994. 120-136. Print.

“persona, n.” OED Online. Oxford University Press, March 2014. Web. 20 May 2014. Publishers, Distributors \& Wholesalers of the United States $4^{\text {th }}$ ed. New York: R. R. Bowker Company, 1982. Print.

Ruppert, Jim. "Paula Gunn Allen and Joy Harjo: Closing the Distance between Personal and Mythic Space.” American Indian Quarterly 7.1 (1983): 27-40.

Scarry, John. "Representing Real Worlds: The Evolving Poetry of Joy Harjo.” World Literature Today 66.2 (1992): 286-292. Web.

Silko, Leslie Marmon. Ceremony. 1977. New York: Penguin Books, 1986. Print.

---. Storyteller. 1981. New York: Penguin Books, 2012. Print.

---. "Yellow Woman and A Beauty of the Spirit." Yellow Woman and a Beauty of the Spirit. New York: Simon \& Schuster, 1996. 60-72. Print.

Thompson, Becky. "Multiracial Feminism: Recasting the Chronology of Second Wave Feminism.” Feminist Studies 28.2 (2002): 337-370. Web.

Urla, Jacqueline, and Alan C. Swedlund. “The Anthropometry of Barbie: Unsettling Ideals of the Feminine Body in Popular Culture.” Deviant Bodies: Critical Perspectives on Difference in Science and Popular Culture (Race, Gender, and Science). Bloomington: Indiana University Press, 1995. 277-313. Print.

Vickery, Ann. Leaving Lines of Gender: A Feminist Genealogy of Language Writing. Hanover: Wesleyan University Press, 2000. Print. 
Vizenor, Gerald. Manifest Manners: Narratives on Postindian Survivance. Lincoln, NE: University of Nebraska Press, 1999. Print.

Wiget, Andrew. "Nightriding with Noni Daylight: The Many Horse Songs of Joy Harjo.” Native American Literatures. Edited by Laura Coltelli. Pisa: Servizio Editoriale Universitario, 1989. 185-196. Print.

---. "Sending a Voice: The Emergence of Contemporary Native American Poetry." College English 46.6 (1984): 598-609. Web.

Zorn, Marilyn. "Women and Western American Literature by Helen Winter Stauffer; Susan J. Rosowski.” Great Lakes Review 8/9.2/1 (Fall 1982-Spring 1983): 92-93. Web. 